\title{
Using mobile communication as a tool for national growth and development
}

\author{
Ademola O. ADESINA, Olubunmi AKERELE and Hanat RAJI-LAWAL \\ Department of Computer Science, \\ Lagos State University, \\ Lagos, Nigeria
}

\begin{abstract}
Mobile communication emergence has brought a whole palette of new possibilities in information sharing not only for individual development but also for national growth. New mobile information devices such as Personal Digital Assistants, Smart-phones, $i$-phones and the like put forward several advantages for personal assistance to the mobile users. They can present up-to-date spatial/non-spatial information in a very individual, dynamic, and flexible way for the mobile users. Mobile communication devices can provide and run many other services and applications which are aimed at presenting to the mobile users the right information in the right moment and at the right place. This improves the economics and strengthens the national growth and development. The evaluations of mobile communication development projects are required in order to have a better understand on its impact on nations' economic, politics and social growth. The research identifies the roles of mobile communication as a means for partnering with the private and public organisations in order to provide better services and awareness for the national growth and development.
\end{abstract}

\section{Keywords}

mobile communication; mobile phone; social network communication; short message service (SMS)

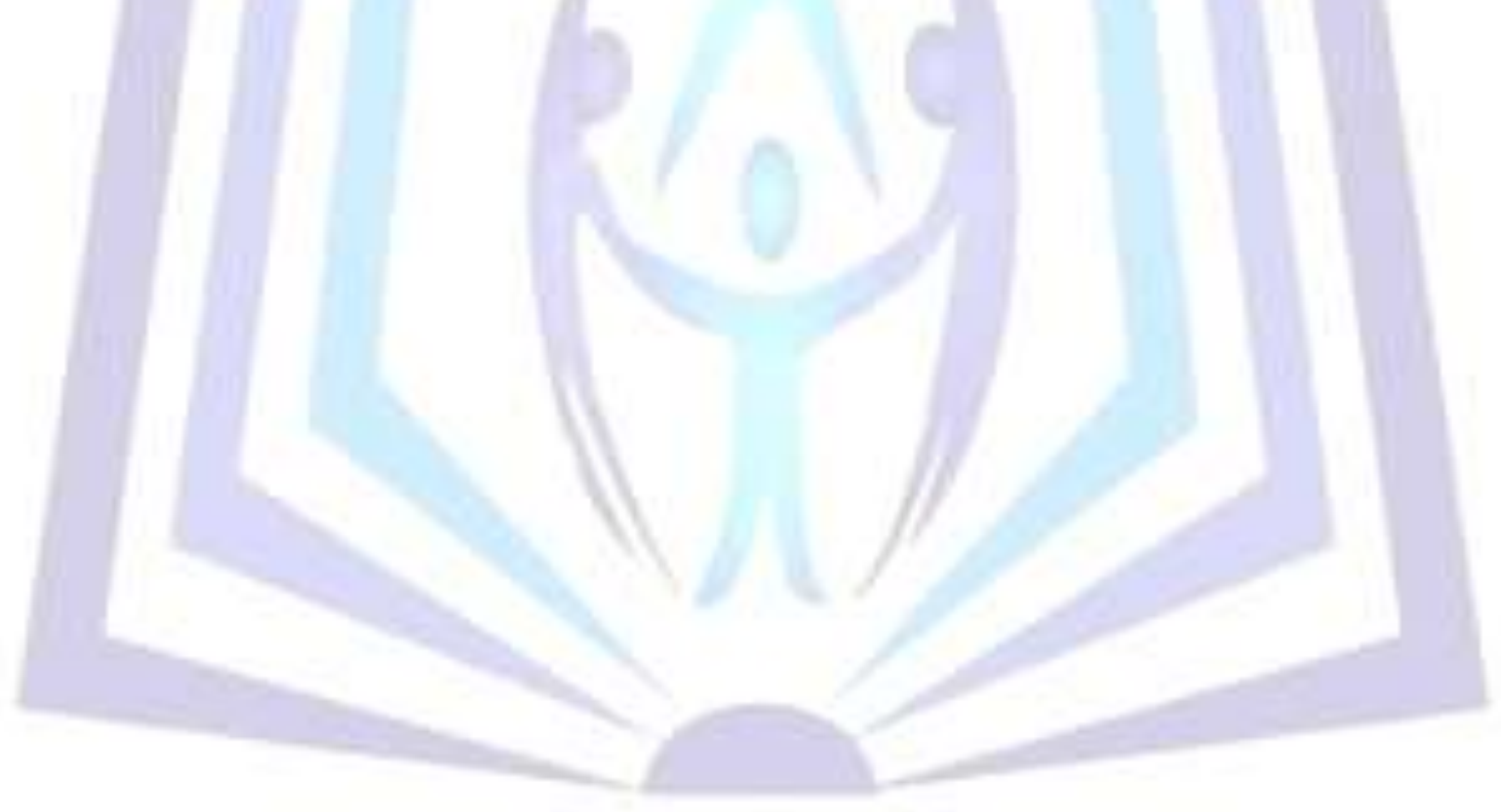

\section{Council for Innovative Research}

Peer Review Research Publishing System

\section{Journal: INTERNATIONAL JOURNAL OF COMPUTERS \& TECHNOLOGY}

Vol. 14, No. 12

www.ijctonline.com, editorijctonline@gmail.com 


\section{Introduction}

Mobile communication is the transmission of digital signals over a distance for the purpose of conversation exchange within the mobile device. The signal is circulated over the territory with the help of the base stations to the service areas where the subscribers or users enjoy the facilities. The communication has allowed people to converse or exchange data or information while they were outside their home, office or on the move. Mobile communication is standardized and regularized by the control unit with the frequency bands assigned by this mobile operator that are re-used repeatedly over countries and even continents [1-3]. Mobile voice and data communication are supported by the network protocols that also support registration and location of mobile users, exchange between base stations as the mobile roams, call initiation, text messaging and so on [2]. Mobile Communication is beyond voice restriction but also include fax, video conferencing and computer data transfer with the introduction of integrated service digital network (ISDN) that has brought the digitalization. The versatility of these mobile devices though is only possible under certain conditions: (screen size and colours, and resolution) are limited compared to analogue and stationary digital visualizations. The size, weight, robustness, and power supply of the MIDs account for further limiting factors [3].

The mobile communication has gone through a series of development from the 1st, 2nd, 3rd and 4th generations. It started with analogue, this supports voice only and the 2nd generation came up with the same purpose but digitalized and based on global system for mobile (GSM) communication technology. It carries voice and short message service (SMS) at very low connecting speed. The 3rd generation came up with high quality to support better service in video calling, mobile gaming and fast internet browsing. The 4th generation is the anticipated generation that is described as the complete evolution in wireless communication. The fourth generation is expected to provide a secure Internet Protocol (IP) solution where voice, data and streamed multimedia can be given to users at anytime and anywhere just like it happened to the early generations.

Available statistics shows that the developed world takes significant part in mobile communication usage. Africa is quickly rising up in the ranks to catch up with the trend in the use of mobile communication gadget. The continent is now the second largest market in the world with over 500 million subscribers [4, 5]. Despite the rise in poverty, diseases, wars and political corruptions mobile communication has become acceptable especially in the middle class population and economic activities [6-8]. The mobile phone has evolved from just a tool for making calls and handle voice; even the basic, low-end mobile phone on the market today is quite powerful; it handles SMS, text and digital storage and often comes with key functions such as an address book to store contact information, a clock that can be used for alarms and reminders, a small torch, a calculator etc. Slightly more advanced models have a music player with an audio recorder, a camera to shoot photographs and videos recording, and surprisingly a platform for games. Most new models are now Internet Protocol (IP) enabled and can function as an internet access point: to upload and download information, for social networking and blogging, send and receive e-mails and stream media. With the spread of mobile money transactions, mobiles have begun to replace wallets as well [9]. As the technology in mobile communication grows increasingly sophisticated it replaces earlier technologies and different technologies are merging into one universal gadget. This can be attributed to internet's open standards, which have accelerated the convergence of voice, SMS, data, video and wireless services. All these have generated new business models, products and services [10].

Mobile phoning, as part of the mobile communication usage, is therefore becoming increasingly important to African countries. Mobile phones have created a platform to expand commercial transactions in a very easy manner and have created a wide array of business opportunities through the expansion of wireless communications. It is spreading fast from social discussions, politics, economics, to religion purpose just to mention a few. Its significant is noticed in the following area of

Infrastructural service - Mobile communication has been observed to improve efficiency of commercial activities, promotion of investment, mobile learning, mobile health, mobile governance, mobile banking and has indeed contributed to other form of empowerment [9, 11, 12]. Mobile banking has eradicated the practice of spending valuable time in the banking as most transactions are now executed on cell phone. Transactions like transfer of funds within the same customer account or to the third party account, payment of bills, account balance retrieval, transaction history retrieval are completed without the customer stepping into the banking hall. Mobile communication has sprung up unprecedented number of cell phone owners. The increased number of cell phone ownership and the acceptability of mobile services have greater effect to the detriment of the use of personal computers.[13]

- $\quad$ Economic service - Mobile communication has been able to boost the economic power of the nation by creating jobs. The mobile operators can make big profits, from the services renders to the users, and in return users pay taxes.[14] The mobile communication operators pay huge amount yearly as taxes over their profits and this is used for national growth and development.[15] Another common economic services gain from mobile communication is noticed in the community where there are charges given for every call made. This is a common practise in Nigeria where people sell a low denomination prepaid scratch cards in the midst of cars trapped or traffic jam or mounting kiosk on streets' corners under an operator logo-branded umbrella or temporary kiosk, selling airtime vouchers and SIM cards, as well as repairing phones, popularly referred to as GSM Engineering.

- $\quad$ Developmental issues - Many cases have been studied that present innovative applications of mobile phones as regards increasing the efficiency of service delivery to the poor e.g. SMS alert to remind patients on 
drug administration, weather forecast information, market prices of items, use of cell-phones cautions while driving and diseases tracking.[16]

From all these perspective, mobile phones are becoming more than just simple phone devices. Numerous technologies are being integrated within its architecture such as Bluetooth, digital cameras, Infrared, General Packet Radio Service (GPRS), E-mail and SMS, IM, MXit, Face book, Internet browsing. There is a need to take the advantage of these opportunities and the understanding of the penetration of mobile phones and the usage patterns across the continent. This technology can influence the social and geographical heterogeneities nature of the people in the continent. Hence, it can lead to the advantage of providing some facilities enjoyed by the advanced world especially in the health related matters.

\subsection{Mobile phone penetration}

Figure 1 shows the recent data on the subscription and penetration of mobile phone in Africa between 2002 and 2012. The subscription and penetration is estimated to be $30 \%$ of Africa total population and expected to reach $53.5 \%$ by the end of 2012.

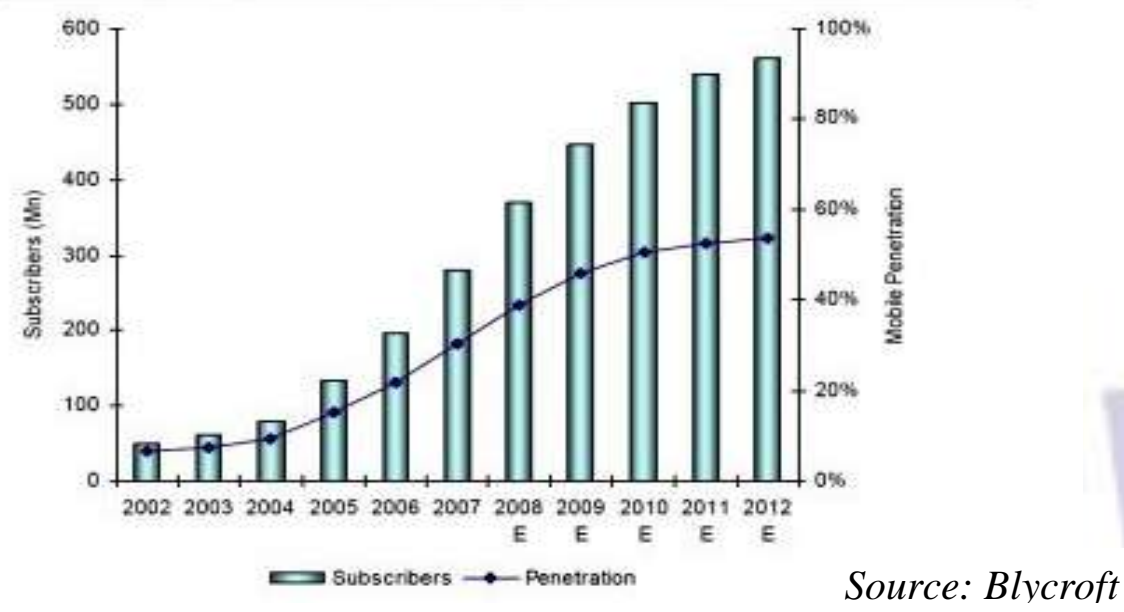

Figure 1. Africa - Mobile subscrintion and nenetration

Figure 2 depicts the rate of penetration of mobile communication in Africa; South Africa, Nigeria, Morocco, Egypt, Algeria and Kenya constitute the key mobile markets in terms of the potential growth. The mobile penetration rate in South Africa is the highest (84\%) and the least is Tunisia ( $8 \%$ ). The rate of mobile penetration in Africa can be used to serve as an avenue for posting information to the unreached, especially in Nigeria.

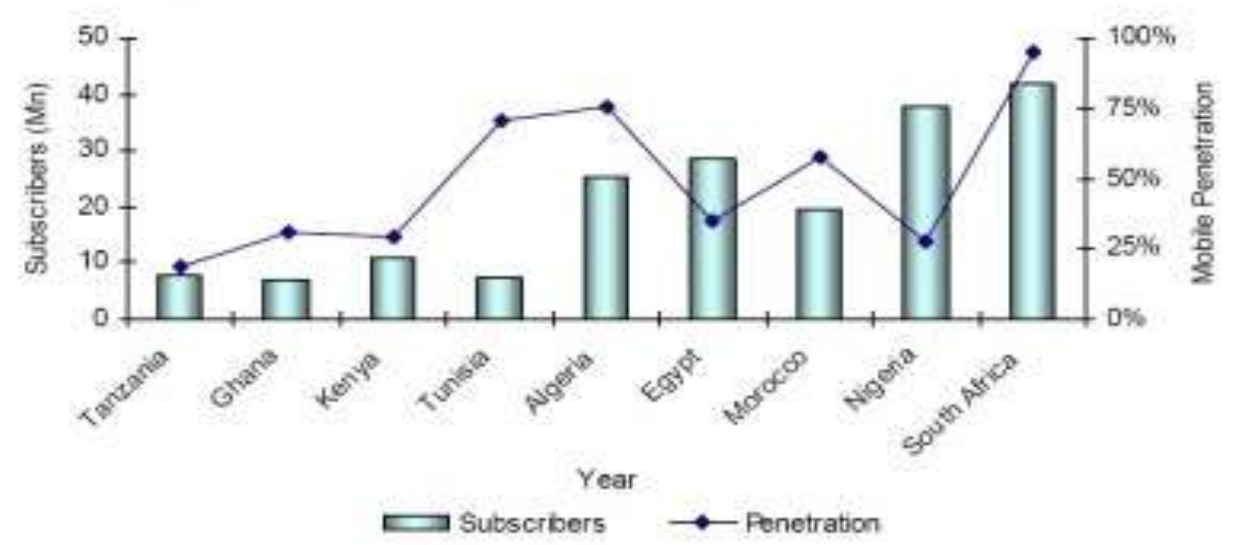

Source: Industry data \& estimates co 2008 Blycroft Ltd.

Figure 2. Africa - Major Mobile Markets

SMS as an integral part of mobile technology can serve the role of information distribution and dissemination. The use of SMS is spreading across several aspects of human endeavour, for instance, it is used in an innovative ways such as pricing information for agricultural products,[10] mobile banking[9] and human rights abuse notifications,[17, 18] and mobile learning.[19] 


\section{Mobile communication and its usage}

Due to technological advancements, the mobile phone has become an all-in-one device that can be carried and used almost anywhere. Internet is going mobile, from desktop to pocket, and innovative simple applications are today a great opportunity for businesses, organizations and governments to reach out and interact with clients and citizens. Mobile technology can also be useful for sophisticated purposes like data analysis, inventory management, architectural construction modeling, mathematical modeling, simulation and mapping. The benefit of mobile technology also includes time saving, ability to mobilize or organize individual, reaching audiences that were previously difficult or impossible to reach, and ability to transmit data more quickly and accurately, ability to gather data more quickly and accurately.

The United Nations focus on the Millennium Development Goals (MDG) with the view of tackling key issues like: health, social, environmental and developmental challenges. It was confirmed that most of the challenges are achievable greatly with the assistance of mobile technology/communication[20] Wireless or mobile communication has come to find solution to these lingering problems faced in the past by connecting families separated by disaster and war, helping emergency relief workers, tracking the impacts of climate change and so much more.[16] Mobile communication therefore stands as a powerful tool for positive change in the world. It is helpful in regard to chronic diseases because it frees physicians from routine office visits while still providing data on patient conditions. This helps doctors focus office care on those requiring more detailed medical assistance.[21] Mobile technology has proved itself relevant in all facets of life, from health, education (learning), government, to commerce.

\section{i. Mobile communication in Health (m-Health)}

Mobile technology has been piloted and proved greatly relevant in a range of health information (e.g. disease outbreak). CellLife in South Africa, for example, is a non-governmental organization in Cape-town that has assigned its worker to monitor about AIDS patients through the programme tagged 'AfterCare'. The organization workers' record information about patient medical status, drug adherence, and the factors that may affect a patient's Anti-Retroviral Therapy (ART). 'AfterCare' workers then relay this information via text message to central CellLife database. The data sent via text message reaches the CellLife server, where a care manager uses a web-based system to access and monitor the incoming patient information. The manager can respond to the need of the 'AfterCare' workers' questions and provide substantial and supplemental information to improve patient treatment or condition. The information collected not only facilities individual patient care, but it is also used to build a database of information on the safety and prevalence of such disease. This has a great impact of combining mobile phone technologies and AIDS management.

\section{ii. Mobile communication in Education (m-Learning)}

M-learning can be viewed in different dimension as:

- the intersection of mobile computing and e-learning through accessible resources within the reach, strong search capabilities for online material, rich interaction, powerful support for effective learning and performance-based assessment and e-learning independent of location, time or space [22, 23].

- a new learning architecture that supports creation, brokerage, delivery and tracking of learning and information contents, using ambient intelligence, personal devices and existing learning contexts, location-independence, personalization, multimedia, instant messaging (text, video) and distributed databases without the restriction of any physical boundary [24, 25].

The evolution of education in an open and distance learning (ODL) environment can be characterized as a continuum and evolution from distance learning (d-learning) to electronic learning (e-learning) to mobile learning (m-learning). M-learning is unique because learners can access the course material, instructions and other course related applications anytime and anywhere. This increases daily attention to learning material, makes learning pervasive as well as boosts the learner's motivation for lifelong learning. Moving from stationary to mobile learning allows ad hoc collaboration and interaction between learners [25].

$\mathrm{m}$-Learning is a technology which covers the spectrum of mobile devices ranging from as simple as by using mobile phones up to high specification PDA with pedagogic applications as students use the device most frequently for communication purposes [25]. The educational content can be delivered via medium such as SMS, MMS or WAP portal. This has the potential to further expand where to learn, how to learn, when to learn and perform various academic activities; hence promoting in all aspects of academic activities with such long learning in an open and distance learning environment $[23,26]$.

\section{iii. Mobile communication in Government (m-Government)}

M-Government is an emerging discipline concerning the rise of advanced mobile and wireless communication technologies that would improve the Quality of Service that government services offer to citizens [27, 28]. M-government is largely a matter of getting public sector IT systems geared to interoperability with citizen's mobile devices [29, 30]. In this regard, developing a coherent $\mathrm{m}$-government framework in the public sector is an important factor. The basic concept for good framework is that it is principle-driven [31]. Five different principles: Interoperability, Security, Openness, Flexibility and Scalability, are important and identifiable as public services framework to incorporate m-government into public administration [27]. 
However, the implementation of m-government is more complex than implementing e-government as governments need to identify the mobile technologies and applications relevant to service efficiency [31]. Although m-government is in its infancy and early stages of development in most countries of the world several governments have already started or are in the process of planning to use mobile services. Usability-driven open platform for m-government is a research and development project of European Consortium that consists of a regional government, three local governments, two research institutions, two universities and a number of technological companies from France, Italy, Germany, Spain, Portugal and Poland [32].

M-government can be applied in the following ways in the public sector [33] :

- M-communication: providing information to the public is not a trivial activity. This is the foundation of citizen empowerment. Without relevant information citizens are unable to form intelligent opinions and, thereby, are unable to act on the issues before them meaningfully.

- M-services: providing a channel of communication between citizens and government via SMS, and enable Government-to-Citizen (G2C) apparel transactions as well. Some examples of existing $m$-services include $m$ parking, $m$-teacher, $m$-library and crisis communication.

- M-democracy: for instance, $m$-Voting and the use of SMS and mobile devices for citizen input to political decision-making is an $m$-government application with tremendous potential to enhance democratic participation.

- $\quad M$-administration: $m$-government also provides opportunities to improve the internal operation of public agencies and government policies up to the grass root.

- Mobile television: with this a new function and service of m-government is achieved through the mobile communication.

\section{iv. Mobile communication in Commerce ( $m$-Commerce)}

M-commerce is defined as a subset of e-commerce where any transaction with a monetary value is conducted in a wireless environment by using mobile devices.[34] Mobile commerce is enabling the development of additional revenue streams for organizations through the delivery of chargeable mobile services [35]. Some of the factors that spring up the development of mobile commerce are technology innovations- such as faster data transmission technologies, more capable more devices equipped with improved computing capacity, enhanced data storage and better user-interfaces, others are increasing penetration and diffusion of mobile phone into society and their associated affordability with its integration into the world economies [36].

The emergence of electronic commerce has caused a revolution in the commercial environment through fundamentally altering the end-to-end process of undertaking commercial transactions through electronic means - for example, sending product orders and invoices through a network [35, 36]. However, with the advent of wireless networks, the rapid proliferation of mobile devices in recent years, and the demand for associated value-added services, in the area of mobile commerce has also emerged. This emergence is causing another revolution in the commercial environment. Mobile commerce makes business mobility a reality; for example, enabling a stock investor to access the latest stock market information and undertake associated transactions using mobile devices connected to wireless network at any time and from any place [35, 37].

Mobile computing has permeated almost all aspects of life - across personal, social and economic systems. The maturity of the technology and its perceived and actual affordances has allowed its application to commerce - yielding the area of m-commerce. The constantly evolving mobile technology landscape comprising devices, software, applications, and networks present challenges for developing mobile commerce applications. The strategic-level focus and understanding of business models for mobile commerce enables adopters to focus on developing innovative value-added solutions that exploit the commercial benefits of mobility.

\section{Social networking communication}

Mobile communication has brought up a virtual social gathering referred to as Social Networking Communication (SNC) like FaceBook, Twitter, MXit, WhatsApp, Instant Messaging (IM) just to mention a few. SNC and IM mostly used by the youths gain fast penetration into urban and rural communities. This has opened up to mobile information accessing and sharing through the mobile data and devices. The era of development of cell phones packaged with exotic and classical popular applications has emerged. For example, smart phones or i-phones has come down to change social networking scenario by making it much easier for new users or group to link to the existing network of friends surely making the spread of information to be easy. What makes SNC and social media extra interesting is that they offer a platform for locally-relevant, content-related, on-demand information disseminating issues on subject matters like health, agriculture, commerce, education and governance. Users that are part of social groups can easily engage as producers of information and not just consumers alone in the course of discussion [38].

These forms of communication have emerged due to developmental trend in mobile technology using some Social Networking Sites (SNS) that create rooms for social, religious, economics, educational interactions and discussions within the users or groups of users, exchanging ideas, and finalizing some decisions. 
FaceBook: allows participants to interact with people they already know offline or to meet new people. From statistics, there are more than one third of 800 million users of mobile devices access FaceBook [39]. It enables its users to present themselves in an online profile, accumulate friends who can post comments on each other's pages, and view each other's profiles. FaceBook members can also join virtual groups based on common interests, see what classes they have in common, and learn each other's hobbies, interests, musical tastes, and romantic relationship status through the profiles [40]. Research has it as evidence that FaceBook users engage in searching for people with whom they have an off-line connection more than they browse for a fresh relationship [41].

Twitter: is a social application with focuses on status updates (tweets) where you are followed and/or are being followed by other users. This is an online application that is blog and social network sites (SNS) driven by cell phone or IM tool. Twitter has mashed up personal publishing and communication, the result being a new type of real-time publishing.[42] It is designed to let users answer the question for instance, 'Abduction of school girls in Chibok, Nigeria, what can the government do? Users have 140 characters for each posting (or 'tweet') to contribute whatever they care to keeping the extra 20 for the user's unique address. Many tweets do participate on the role of country security system, poverty level, corruption practices etc., while others may ignore but rather shows interests to other tweets or online resources that are found interesting, musings, or questions by the users or groups of users. Like the fundamental of SNS, Twitter involves mini-updates, it let users create formal friendships, which collectively establish numerous and interconnected networks of users. In addition, Twitter works with cell phones and other SMS clients, making it an easy way for mobile users to stay in touch virtually anywhere [43].

Some other pedagogical applications of Twitter can be for dissemination of teaching resources, locating original sources of ideas, quotes. Twitter allows focus and concrete feedback to students to refine their thinking and improve their skills, fostering professional connections, informal research, for story-telling, class chatter, follow a professional, get feedback on ideas, programs, make appointments, event updates, live coverage of events, build trust, build a community [44]. Are there any real development benefits in Twitter and sending tweets? Even though most of the tweets are time consuming babbling, some tweets do play a role. Anecdotal stories tell us how Twitter can be used to mobilise, create social movements and be a helpful tool during emergencies in getting information out. In Iran, following the 2009 Iranian Election, Twitter was used as a rallying tool and as a method of communication with the outside world after the Iranian government blocked several other modes of communication. In Uganda, Twitter was used to report incidents and violence during the September Kampala riots in 2009. In a situation where radio stations were closed down, television shows censored, networks jammed, and public transportation down, Twitter proved to be a good one-to-many solution.

MXit is a mobile instant messenger and social networking application that allows the user to chat with optimised webenabled mobile phones. It is developed in South Africa and has become extremely popular due to cost factors and critical mass of users. The low cost of using MXit is one of the reasons that MXit is popular with teenagers.[45] It is used as an educational technology-enabled device to teach subjects like Mathematics in South African [46, 47] which is referred to as Dr. Maths this can be introduced as part of curriculum in the high school.

\section{SMS communication}

Of significant in mobile phoning is the text messages (popularly called SMS). SMS is the transmission of short text messages to and from a mobile phone, fax machine and/or IP address. Usually, the messages length falls within 160 alphanumeric characters with neither images nor pictures/graphics. It is operational within mobile phone networks basically by mobile phone networks of GSM, Time Division Multiple Access (TDMA) and Code Division Multiple Access (CDMA). Mobile phone penetration and acceptability (Section 2.0) of existing services by SMS users have sprung up the glory of usage that spread to various SMS-based services.

Every SMS sent will be received by Short Message Service Centre (SMSC), which must then direct it to the appropriate mobile devices. An SMSC is software that resides in the operator's network and manages the processes including the queuing of the messages, senders' billing and returning of the receipts if necessary. SMSC is a store-and-forward system for short messages. In order to achieve this, SMSC sends a SMS Request to the Home Location Register (HLR) to look for the roaming customer. Once the HLR receives the request, it will respond to the SMSC with the subscriber's status (active or inactive) where subscriber is roaming. If the response is inactive, then the SMSC will hold onto the message for a period of time. When the subscriber accesses his device, the HLR sends a SMS notification to the SMSC, and the SMSC will attempt delivery. The SMSC transfers the message in a Short Message Delivery Point-to-Point format to the serving system. The system pages the device, and if it responds, the message gets delivered. The SMSC receives verification that the message was received by the end user, then categorizes the message as sent and will not attempt to send again.

SMS can be sent and received simultaneously with GSM voice, data and fax calls. This is possible because voice, Data and Fax calls take over a dedicated radio channel for the duration of the call, SMS travel over and above the radio channel using the signaling path. With this, users of SMS rarely, if ever, get busy or engaged as they do during peak network usage times.

SMS communication supports multiple SMS broadcast where many contacts receive the same message. SMS concatenation (stringing several SMS together) and SMS compression (getting more than 160 characters of information within a single short message) have been defined and incorporated in the GSM SMS standards. The use of SMS capabilities involves the following features:

- A subscription to a mobile telephone network that supports SMS 
- A mobile phone that supports SMS

- The use of SMS must be enabled by the network operator for the user.

- User's knowledge of how to send and read an SMS

- Destination to send an SMS to, or to receive a message from e.g. mobile phone, fax machine, PC or Internet address

\subsection{Benefits and applications of SMS}

Besides convenience, flexibility and seamless integration of messaging services and data accessing provide from the services of SMS, other benefits of SMS include:

- Delivery of notification and alerts

- Guaranteed message delivery

- Reliable, low cost communication mechanism for concise information

- Ability to screen messages and return calls in a selective and choosy manner

- Increased subscriber productivity

- Delivery of same message to multiple subscribers at a goal

- Ability to receive diverse information

- E-mail generation

- Creation of user groups

- Integration with other data and internet-based applications

The applications of SMS are explained as follows:

1. SMS acts as the learning tools to enhance learners understanding of the printed modules. SMS can be seen as the first step of pioneering platform in mobile learning because the technology is relatively cost-effective, reliable and majority of learners owned mobile phones. Using a mobile phone, students can easily learn from any place whenever convenient and suitable to them; like in buses, at home, in gardens and parks, even at market places [48]. The belief is that SMS has the potential to be an additional driver to support the self-learning processes. SMS technology is considered to be a catalyst for potential mobile learning. It also serves as another supporting learning tool used in the suite of educational technologies and practices which are being implemented in a variety of learning scenarios where the shared objective is to develop self-learning concept taking place not only in online environment, but also supported face-to-face tutorial sessions as well as whilst students are mobile [48].

2. SMS is relevant in mobile marketing (or wireless marketing) whereby there is an exchange of information or communications in an interactive and relevant manner using the mobile network devices [49]. The communication is enhanced with the use of either wireless local area networks or satellite network to broadcast the signal. Mobile marketing has been identified as a tool that can improve the status of developing countries by increasing their socio-economic development [50]. This is assured with the increase in the purchasing power of most people to own mobile phones and having access to ICT facilities like Internet, Radio and Television. Over the past few years SMS has become a legitimate advertising channel 1 in some parts of the world especially in the area of mobile advertising [49]. The SMS mobile marketing strategy adopts the push technique whereby information and marketing flow from the producer to the customer2. The method not only allows the marketer to take initiatives and send messages directly to the consumer irrespective of the consumer willingness to receive the message not only boast the sales within a short time. The pull technique involves sending message that are initiated by the consumer2. Through mobile marketing and the use of mobile phones and messaging technology, farmer, for instance, can get access to valuable market data by sending cheap SMS text messages across geographical distances and confirm the cost and availability of agricultural items [49].

3. SMS common activity in health matters can be noticed in the area of appointment reminders, medication taking, telemedicine, accessing patient records, communication of laboratory test results, measuring treatment compliance, raising health awareness, monitoring patients illness, and physician decision support [21, 51] and other virtual health assistants. Patients make use of the SMS tool to keep in touch with their family and friends during hospitalization [52], for instance, SMS can provide the missing link - between a hospital and its field worker, patients, support group members, or community health workers in their respective villages [53]. The trends and developments of mobile communications has reflected in an increasing utilization of cell phones and SMS in the health services [54]. SMS is inexpensive in terms of cost and are applied quietly without disturbing other patients when they are not occupied with any medical procedures [52]. It is confirmed that SMS offers an alternative or

\footnotetext{
${ }^{1}$ www.oppapers.com/essays/Mobile -Marketing/609752

${ }^{2}$ www.electronicgovernment.se/AMIS/about.htm
} 
supplementary means of providing and receiving social support of patients in hospital [52] With the ubiquity of mobile phones, texting is an excellent way to send reminders that trigger health-related behaviours, educating people about health research findings, and notifying people on urgent information about a new epidermis [55].

4. SMS is used as an administrative support, a case of University of Birmingham can be cited, where a link was established between an e-mail and text message services to support Administrative communication in the institution [56]. The idea behind the project is to integrate administrative staff and students experience together, by communicating to the students while the students were able to perfectly and effectively receive and act on the text messages that were sent. Message can be issued on change and cancellations of class, assignment submission and collection, extra lectures or activities within the group or the class, warning messages for absenteeism, instruction for assignment submission and courteous or well-wishing greetings. SMS services can be extended to dissemination of enrolment information, grade/results release, university announcement, internship opportunity can be sent or retrieved by the students through this technology [57].

5. SMS roles in Library services cannot be over emphasis in the area of administrative support. SMS-based library information can be sent to students to remind them of book reservations, renewals and overdue of borrowed material, books arrival/acquisition. Other areas in which SMS can be incorporated into Library services are in the dispensation of basic information alerts like period of operations, workshops and lecture. At the end of the day, these services promote or enhance the quality of library services delivery within the University system.

\section{Conclusion}

The paper looked at the advantages that can be derived from the use of mobile communication for national growth and development if it is adopted. The penetration, acceptability and accessibility of mobile technology are factors to be considered in bridging the gap for information dissemination to the grass-root. The idea of having multiple numbers of handsets with each handset subscribing to different network can be recommended as a good way to create awareness of the government policy, market trend, and democratic process to the citizens. As part of the advantages, mobile banking has built additional service upon existing financial services, very easy and at reduced cost both to customers and financial service providers. It is hope that the percentage can be used to realize the vast untapped potentials for national growth and development. This can assist the policy makers, service managers and other practitioners to take advantage with the intention of providing more services to the populace.

\section{Bibliography}

[1] N. Borisov, I. Goldberg, and D. Wagner, "Intercepting mobile communications: The insecurity of $802.11, "$ presented at the 7th Annual ACMIIEEE International Conf on Mobile Computing and Networking, Mobicom'01, Rome, Italy, 2001.

R. Steele and L. Hanzo, "2nd Edition Second and Third Generation Cellular and WATM Systems," Mobile Communications, 1995.

[3] T. Reichenbacher, "The World In Your Pocket - Towards A Mobile Cartography," presented at the Proceedings of the 20th International Cartographic Conference (CDROM), Department of Cartography Technical University Munich Arcisstr. 21, D-80333 Munich, Germany tumasch@bv.tum.de, 2001.

A. Wesolowski, N. Eagle, A. M. Noor, R. W. Snow, and C. O. Buckee, "Heterogeneous Mobile Phone Ownership and Usage Patterns in Kenya " PLOS ONE, vol. 7, 2012.

[5] K. Langmia, "Social media technology and the 2011 Presidential Election in Cameroon," presented at the International Conference on ICT for Africa Harare, Zimbabwe, 2013.

[6] A. Chabossou, C. Stork, M. Stork, and P. Zahonogo, "Mobile Telephony Access \& Usage in Africa " presented at the Proceedings of the International Conference on Information and Communication Technologies and Development (ICTD), IEEE, Doha, 2009.

[7] M. Tomitsch, F. Sturm, M. Konzett, A. Bolin, I. Wagner, and T. Grechenig, "Stories from the Field: Mobile Phone Usage and its Impact on People's Lives in East Africa," presented at the Proceedings of the International Conference on Information and Communication Technologies and Development (ICTD'10). 2010.

[8] J. Hellström. (2010). The Innovative Use of Mobile Applications in East Africa.

[9] A. O. Poroye, "Secure contactless mobile financial services with near field communication," Masters, Department of Computer Science, University of the Western Cape, Cape Town, South Africa, 2011.

[10] W. N. Karugu, "Kenya agricultural commodity exchange (KACE): Linking small farmers to national and regional markets," 2011.

[11] D. Bishanga and H. Kimaro, "Mobile Phone Technology: A Gateway to Address Gender Obstacles in Improving Access to Reproductive and Child Health Services by Women and their Partners " presented at the IST Africa 2012 Conference Tanzania, 2012.

[12] V. W. Consulting, "mHealth for Development: The Opportunity of Mobile Technology for Healthcare in the Developing World " Vital Wave Consulting., Washington (DC), Berkshire(UK),2009. 


\section{ISSN 2277-3061}

[13] K. Kahandawa and J. Wijayanayake, "Impact of Mobile Banking Services on Customer Satisfaction: A Study on Sri Lankan State Commercial Bank," International Journal of Computer and Information Technology, vol. 3, pp. $546-552,2014$.

[14] G. Baez, "THE IMPACT OF MOBILE SERVICES IN NIGERIA: How Mobile Technologies Are Transforming Economic and Social Activities," Pyramid Research World Headquarters, 10 Canal Park, Cambridge, MA 02141, USA2010.

[15] E. M. Agwu and A.-L. Carter, "Mobile phone banking in Nigeria: Benefits, Problems and Prospects " International Journal of Business and Commerce, vol. 3, pp. 50-70, 2014.

[16] K. S. Lissy, J. T. Cohen, M. Y. Park, and J. D. Graham, "Cellular Phone Use While Driving: Risks and Benefits," Harvard School of Public Health, Boston, Massachusetts2000.

[17] V. Gratzner, D. Naccache, and D. Znaty, "Law Enforcement, Forensics and Mobile Communications," presented at the Proceedings of the Third IEEE International Workshop on Pervasive Computing and Communication Security, 2006.

[18] K. D. Lutes and R. P. Mislan, "Challenges in Mobile Phone Forensics," presented at the 5th International Conference on Cybernetics and Information Technologies, Systems and Applications (CITSA), 2008.

[19] D. Naughton, "A Review of Text Messaging (SMS) as a Communication Tool for Higher Education," (IJACSA) International Journal of Advanced Computer Science and Applications, , vol. 5, 2014.

[20] UNCTAD, 2005.

[21] D. West, "How mobile devices are transforming healthcare," Issues in technology innovation, 2012.

[22] C. Lefebvre, "Integrating cell phones and mobile technologies into public health practice: A social marketing perspective: Social marketing and health Communication.," Health Promotion practice, vol. 10, pp. 490-494, 2009.

[23] N. Safie, "The use of Short Messaging System (SMS) as a supplementary learning tool in Open University Malaysia (OUM)," presented at the 18th Annual Conference Association of Asian Open Universities (AAOU) Shanghai, China, 2004.

[24] G. Clough, A. C. Jones, P. Mcandrew, and E. Scanlon, "Informal learning with PDAs and smartphones.," Journal of Computer Assisted Learning, vol. 24, pp. 359-371, 2008.

[25] J. Mueller, E. Wood, D. De Pasquale, and R. Cruikshank, "Examining Mobile Technology in Higher Education: Handheld Devices," International Journal of Higher Education, vol. 1, pp. 43-54, 2012.

[26] H. Sheng, K. Siau, and F. F.-H. Nah, "Understanding the values of mobile technology in education: a valuefocused thinking approach," SIGMIS Database, vol. 41, pp. 25-44, 2010.

[27] B. Yu and I. Kushchu, "The value of mobility for e-Government," presented at the The 4th European conference on E-Government, Castle Dublin, Ireland, 2004.

[28] I. Kushchu and H. Kuscu, "From E-Government to M-government: Facing the Inevitable," presented at the The 3rd European conference on E-Government (ECEG03), Trinity College, Dublin, 2003.

[29] K. Amailef and J. Lu, "A mobile-based emergency response system for intelligent m-government services," Journal of Enterprise Information Management, vol. 24, pp. 338 - 359, 2011.

[30] M. Alrazooqi and R. D. Silva, "An m-government solution proposal for Dubai government," presented at the Proceedings of the 9th WSEAS international conference on Telecommunications and informatics, Catania, Italy, 2010.

[31] A. Maio, "Toward a wireless public Sector," Gartner Research, 2002.

[32] A. Martin, J. Gonzalez, J. Gonzalez, and A. Vilas, "USE-ME.GOV: Usability open platform for mobile government," presented at the 2nd Open Source World Conference, Merida, Spain, 2005

[33] T. El-Kiki and E. Lawrence, "Government as a mobile enterprise: real-time, ubiquitous government," presented at the Third International Conference on Information Technology: New Generations, Las Vegas, Nevada, 2006.

[34] C. S. Yap and J. W. H. Hii, "Factors Affecting the Adoption of Mobile Commerce in Malaysia," Icfai Journal of Information Technology, vol. 5, pp. 24-37, 2009.

[35] K. Hameed, K. Ahsan, and Y. Weijun, "Mobile Commerce and Applications: An Exploratory Study and Review," Journal of computing, vol. 2, 2010.

[36] R. Tiwari, S. Buse, and C. Herstatt, "From electronic to mobile commerce," ed: Institute of Technology and Innovation Management Hamburg University of Technology, 2006.

[37] P. Lidderdale, "Importance of enterprise architecture," ed: Terry College of Business, University of Georgia, 2009. 
[38] W. Uys, A. Mia, G. J. Jansen, H. Van Der Schyff, M. A. Josias, M. Khusu, et al., "Smartphone Application Usage Amongst Students at a South African University," presented at the IST-Africa 2012 Conference Proceedings Paul Cunningham and Miriam Cunningham (Eds) IIMC International Information Management Corporation, 20122012.

[39] S. B. Baggett and M. Williams, "Student Behaviors and Opinions Regarding the Use of Social Media, Mobile Technologies, and Library Research," EJournals Virginia Libraries, vol. 58, pp. 19-22, 2012.

[40] N. B. Ellison, C. Steinfield, and C. Lampe, "The Benefits of Facebook "Friends:" Social Capital and College Students' Use of Online Social Network Sites," Journal of Computer-Mediated Communication vol. 12, pp. 11431168, 2007.

[41] C. Lampe, N. Ellison, and C. Steinfield, "A Face(book) in the crowd: Social searching vs. social browsing. ," presented at the 2006 20th Anniversary Conference on Computer Supported Cooperative Work. , New York: ACM Press, 2006.

[42] G. Grosseck and C. Holotescu, "Can we use twitter for educational activities?," presented at the The 4th International Scientific Conference eLearning and Software for Education, Bucharest, 2008.

[43] J. Jantsch. (2009). Using twitter for business.

[44] C. M. Elavsky, C. Mislan, and S. Elavsky, "When talking less is more: exploring outcomes of Twitter usage in the large-lecture hall," Learning, Media and Technology, vol. 36, pp. 215-233, 2011/09/01 2011.

[45] L. Butgereit, "How Dr Math reaches Pupils with Competitions and Computer Games by using MXit," presented at the IST-Africa 2009 Conference Proceedings Paul Cunningham and Miriam Cunningham (Eds) IIMC International Information Management Corporation, 2009, 2009.

[46] M. Ford and A. Botha, "A pragmatic framework for integrating ICT into education in South Africa," presented at the IST-Africa, 2010, IEEE, 2010.

[47] L. Butgereit, "Dr Math: Using instant messaging in a mathematics tutoring project," presented at the Proceedings of the 3rd International Conference on e-Learning Academic Conferences Limited, 2008.

[48] A. Kafyulilo, "Access, use and perceptions of teachers and students towards mobile phones as a tool for teaching and learning in Tanzania," Education and Information Technologies, pp. 1-13, 2012.

[49] P. K. Jaiswal, "SMS based information systems," MSc., School of computing, University of Eastern Finland, 2011.

[50] A. G. Mwakaje, "Information and Communication Technology for Rural Farmers Market Access in Tanzania " Journal of Information Technology Impact vol. 10, pp. 111-128, 2010

[51] V. Ostojic, B. Cvoriscec, S. Ostojic, D. Reznikoff, A. Stipic-Markovic, and Z. Tudjman, "Improving asthma control through telemedicine: a study of short-message service," Telemed J E Health, vol. 11, 2005.

[52] S. Bergvik and R. Wynn, "The use of short message service (SMS) among hospitalized coronary patients," General Hospital Psychiatry, vol. 34, pp. 390-397, 2012.

[53] J. Nesbit, "Building an SMS Network into a Rural Healthcare System," 2011.

[54] R. A. Atun, S. R. Sittampalam, and A. Mohan, "Uses and benefits of SMS in healthcare delivery," Discussion paper. London: Imperial College,, 2005.

[55] B. Fogg and E. Allen, "10 Uses of texting to improve health," presented at the Persuasive '09, Claremont, California USA, 2009.

[56] L. Naismith, "Using text messaging to support administrative communication in higher education," Active Learning in Higher Education, vol. 8, pp. 155-171, 2007.

[57] S. Pramsane and R. Sanjaya, "Mobile education services on SMS and their architecture comparison," presented at the Proceedings of the Third International Conference on e-Learning for Knowledge-based Society, 2006. 